\title{
Correspondence:
}

\section{Combining fragmented QRS and TIMI score for predicting in-hospital short-term prognosis after acute myocardial infarction*}

\author{
Qin-hui SHENG ${ }^{\dagger \S}$, Chih Chi HSU ${ }^{\S}$, Jian-ping LI, \\ Tao HONG, Yong HUO \\ Department of Cardiology, Peking University First Hospital, \\ Beijing 100034, China \\ †E-mail: shengqinhui@126.com
}

https://doi.org/10.1631/jzus.B1700413

Acute myocardial infarction (AMI) has a high mortality rate and poor prognosis for patients. The primary causes of death are arrhythmia and heart failure. For patients admitted because of myocardial infarction, various risk evaluations are initiated to foresee possible complications. The thrombolysis in myocardial infarction (TIMI) risk score, which can be used to predict the prognosis and the need for revascularisation, is the most convenient and commonly used system, but is inadequate for AMI patients on admittance. Fragmented QRS (fQRS) has been shown to be a valuable electrocardiographic (ECG) index for predicting the prognosis of patients with coronary heart disease (Das et al., 2006, 2007). Also, fQRS is considered to predict an increased likelihood of a poor outcome and mortality in patients with coronary artery disease (CAD) (Güngör et al., 2016), even for some successfully revascularized AMI patients (Tanriverdi et al., 2017; Zhang et al., 2017). So what would happen if fQRS and the TIMI risk score were combined? This study focused on the investigation of the short-term prognostic value of fQRS combined with the TIMI risk score for patients with AMI.

\footnotetext{
$\$$ Corresponding author

$\S$ The two authors contributed equally to this work

* Project supported by the National Key Technology R\&D Program of China (No. 2011BAI11B06)

(D) ORCID: Qin-hui SHENG, https://orcid.org/0000-0002-4592-1917

(C) Zhejiang University and Springer-Verlag GmbH Germany, part of Springer Nature 2018
}

Three hundred patients with AMI under continuous treatment in the coronary care unit (CCU) and general wards were selected for this study. Patients with severe valvular disease, congenital heart disease or pacemaker implantation, or other severe organ disease or dysfunction such as cancer, liver or kidney failure, neuro or mental disease, were excluded. Seven clinical variables were used to determine the TIMI risk score, each adding a value of 1 point if present (Antman et al., 2000): (1) age >65 years, (2) $\geq 3$ classical risk factors for CAD, (3) known CAD, (4) use of aspirin in the past $7 \mathrm{~d}$, (5) severe angina in the past $24 \mathrm{~h}$, (6) elevated cardiac markers, (7) STdeviation $\geq 0.5 \mathrm{~mm}$.

A serial 12-lead ECG (filter range, 0.5-100.0 Hz; AC filter, $25 \mathrm{~mm} / \mathrm{s}, 10 \mathrm{~mm} / \mathrm{mV}$ ) was performed right after the patients were admitted to hospital and rechecked after $1,3,6,12,24 \mathrm{~h}$, and every day after a percutaneous coronary intervention (PCI) until they were discharged or died. ECG monitoring was required upon admission as well as Holter electrocardiogram and echocardiography on the third day after admission. Any fQRS detected was deemed to be positive fQRS, regardless of how many leads were involved or on which days it appeared. Patients with a left ventricular ejection fraction $<40 \%$ were deemed to have left ventricular systolic dysfunction (LVSD). Malignant cardiac arrhythmia included polymorphic ventricular extrasystoles, ventricular tachycardia, and ventricular fibrillation. The secondary observation endpoint involved more than one cardiac incident, including cardiac arrest, malignant ventricular arrhythmia, and acute heart failure. Patient evaluation would end with either discharge after recovery or all-cause death. The Student's $t$-test was used for comparison of averages and the chi-square test for comparison of rates. A 95\% confidence interval (CI) of relative risk (RR) was taken as suggesting the 
presence of a clinically significant risk factor. A $P$-value of $<0.05$ was taken to indicate statistical significance.

Diagnostic standards for fQRS are shown as follows (Das et al., 2006, 2007): (1) Narrow fQRS: new or different morphological triphasic QRS waves in the regular 12-lead ECG (RSR' type) or multiphasic waves, with or without a Q-wave in two or more corresponding leads of the coronary arterial branch, except for the complete (QRS $\geq 120 \mathrm{~ms}$ ) or incomplete bundle branch block and intraventricular block; (2) Wide fQRS (f-wQRS): for a wide QRS wave of bundle branch block (QRS $>120 \mathrm{~ms}$ ), an $\mathrm{R}$-wave or S-wave with more than two notches in two sequential leads was observed (f-LBBB QRS, f-RBBB QRS); for a wide QRS complex of premature ventricular contractions (PVCs), R-waves showed two notches and time intervals greater than $40 \mathrm{~ms}$ between the two notches of the QRS waves in two or more sequential leads (fragmented PVCs). Electrocardiograms were compared with previous electrocardiograms if available, to confirm fQRS or that pathologic $\mathrm{Q}$ waves were the result of a new onset. The different sorts of fQRS are shown in Fig. 1.

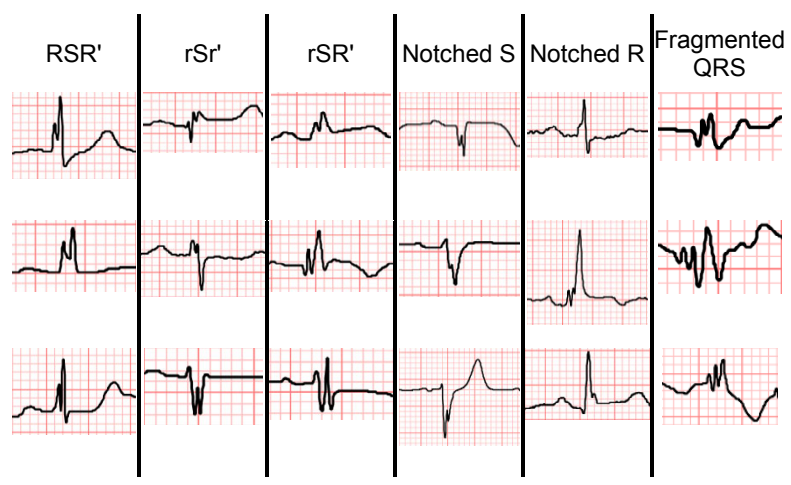

Fig. 1 Different sorts of fQRS

The 300 patients included 204 males and 96 females with an average age of $(68.48 \pm 0.71)$ years. Two hundred and one patients had NSTEMI and the remaining 99 had STEMI according to the discharge diagnosis. During hospitalization, 184 patients received PCI treatment, while the remaining 116 patients received a conservative treatment plan including dual-antiplatelet, anticoagulation with low molecular weight heparin, statins, and nitrates, $\beta$ blockers, angiotensin converting enzyme inhibitor (ACEI) or angiotensin receptor blocker (ARB), which were given based on the condition of the patients and whether they had complications. One hundred and sixty-nine patients were found to have fQRS. There were no significant differences in comparison of age, sex, and location of infarct between the groups with or without fQRS (Table 1).

Table 1 Comparison of basic information for the fQRS and non-fQRS groups

\begin{tabular}{|c|c|c|c|}
\hline \multirow[b]{2}{*}{ Parameter } & \multicolumn{2}{|c|}{ Patient number ${ }^{*}$} & \multirow[b]{2}{*}{$P$-value } \\
\hline & $\begin{array}{c}\text { fQRS } \\
\text { (169 cases) }\end{array}$ & $\begin{array}{l}\text { Non-fQRS } \\
\text { (131 cases) }\end{array}$ & \\
\hline Age (year) & $70.3 \pm 0.98$ & $66.05 \pm 1.13$ & 0.127 \\
\hline Male & 81 & 123 & 0.241 \\
\hline Smoking & $63(21.0 \%)$ & $96(32.0 \%)$ & 0.376 \\
\hline Hypertension & $92(30.7 \%)$ & $128(46.7 \%)$ & 0.203 \\
\hline Dyslipidemia & $44(14.7 \%)$ & $77(25.7 \%)$ & 0.104 \\
\hline Diabetes & $62(20.7 \%)$ & $85(28.3 \%)$ & 0.951 \\
\hline $\begin{array}{l}\text { History of coronary } \\
\text { heart disease }\end{array}$ & $57(19.0 \%)$ & $88(29.3 \%)$ & 0.361 \\
\hline $\begin{array}{l}\text { Familial history } \\
\text { of coronary } \\
\text { disease }\end{array}$ & $22(7.3 \%)$ & $44(14.7 \%)$ & 0.106 \\
\hline $\begin{array}{l}\text { LAD stenosis } \\
\quad \geq 50 \%\end{array}$ & $62(31.8 \%)$ & $107(54.9 \%)$ & 0.861 \\
\hline $\begin{array}{l}\text { RCA stenosis } \\
\geq 50 \%\end{array}$ & $55(28.2 \%)$ & $86(44.1 \%)$ & 0.330 \\
\hline $\begin{array}{l}\text { LCX stenosis } \\
\quad \geq 50 \%\end{array}$ & $54(27.7 \%)$ & $83(42.6 \%)$ & 0.268 \\
\hline $\begin{array}{l}\text { Malignant cardiac } \\
\text { arrhythmia }\end{array}$ & $21(7.0 \%)$ & $9(3.0 \%)$ & 0.001 \\
\hline LVEF $<40 \%$ & $38(13.4 \%)$ & $26(9.2 \%)$ & 0.010 \\
\hline
\end{tabular}

* Values are expressed as number (percentage) of patients, except age (mean $\pm \mathrm{SD}$ ) and male (number). LAD: left anterior descending coronary artery; RCA: right coronary artery; LCX: left circumflex coronary artery; LVEF: left ventricular ejection fraction

Although the TIMI score was first used for NSTEMI rather than STEMI (Antman et al., 2000), we found that the categories in the score could apply to both NSTEMI and STEMI. Sometimes it might take hours for the patient to develop the characteristics of certain ST, whether elevate or deviate, and it could be hard to distinguish NSTEMI from STEMI patients following admission. Therefore, we used this TIMI score to initially grade patients with AMI. The same situation may apply to many other clinical scoring systems that could be used initially under different circumstances. By using the TIMI score and fQRS, the sensitivity and specificity for the prediction of malignant cardiac arrhythmia were $50.0 \%$ and 
$91.1 \%$, and for the detection of LVSD were $60.9 \%$ and $84.1 \%$, respectively. When using the TIMI score alone, the sensitivity and specificity were, respectively, $23.3 \%$ and $88.6 \%$ for the prediction of mortality, $23.4 \%$ and $74.3 \%$ for the prediction of LVSD, and $30.5 \%$ and $79.6 \%$ for the prediction of malignant cardiac arrhythmia. In the combined analysis for the group with a TIMI risk score of $\geq 4$ and the group with a TIMI risk score of $<4$, both of which had positive fQRS, the group with the score of $\geq 4$ had a much higher incidence of LVSD, and the rate was three times that of the non-fQRS group $(P<0.05)$. From the group with a TIMI risk score of $<4$, we could see that in combination with the presence of fQRS, the numbers of cases with malignant cardiac arrhythmia, LVSD, and mortality were all significantly higher than those observed in the negative fQRS group. As there was no report of malignant cardiac arrhythmia in patients of negative fQRS, the specificity was therefore $100.0 \%$. The incidence of LVSD was four times that of the non-fQRS group $(P=0.065)$, and the mortality rate was nine times higher $(P=0.014$; Table 2).

Positive fQRS patients were first grouped by TIMI risk score and then by the treatment they received (either with or without PCI), before they were all evaluated for the conditions of malignant cardiac arrhythmia, LVSD, or mortality. In the group with a
TIMI risk score of $\geq 4$, the incidence rates of LVSD and mortality were significantly higher in patients without PCI (Table 3). This effect was even more pronounced in the number of deaths $(P<0.01)$. In the group with a TIMI risk score of $<4$, significant differences were seen in the rates of malignant cardiac arrhythmia and mortality for patients without PCI treatment. The mortality rate was dramatically increased $(P<0.01)$.

Many studies have shown the important clinical value of risk stratification and prognosis for patients of AMI. The TIMI risk score was established as an evaluative method by two triphase international experiments with random and double-blinded design for prognosis of coronary heart disease. However, discrepancies between the predictions and the actual outcomes for patients were always observed in clinical settings, because the method focused mainly on immediate evaluation of each patient's condition upon admission and the need for any emergency PCI treatment, and was less able to provide valuable information for short-term prognosis of hospitalized patients. Das et al. (2009) conducted follow-up for 5.5 years on 998 patients with acute coronary syndrome and found that the mortality rates for an fQRS group and a non-fQRS group were $34 \%$ and $26 \%$, respectively, and that positive fQRS was the significant independent predictive factor for acute coronary

Table 2 Short-term prognostic outcomes of patients with acute myocardial infarction as evaluated by the fQRS with TIMI risk score

\begin{tabular}{|c|c|c|c|c|c|c|}
\hline \multirow{2}{*}{ Outcome } & \multicolumn{3}{|c|}{ TIMI score $\geq 4$} & \multicolumn{3}{|c|}{ TIMI score $<4$} \\
\hline & Positive fQRS & Negative fQRS & $P$-value & Positive fQRS & Negative fQRS & $P$-value \\
\hline $\begin{array}{l}\text { Malignant cardiac } \\
\text { arrhythmia }\end{array}$ & $15(6.5 \%)$ & $7(3.0 \%)$ & 0.263 & $8(11.4 \%)$ & $0(0.0 \%)$ & 0.006 \\
\hline LVSD & $39(18.1 \%)$ & $15(6.9 \%)$ & 0.014 & $8(12.1 \%)$ & $2(3.0 \%)$ & 0.064 \\
\hline Death & $31(13.5 \%)$ & $18(7.8 \%)$ & 0.315 & $9(12.9 \%)$ & $1(1.4 \%)$ & 0.014 \\
\hline
\end{tabular}

Data are expressed as number (percentage) of patients

Table 3 Correlation between the fQRS with TIMI risk score and the short-term prognosis for patients after PCI intervention

\begin{tabular}{|c|c|c|c|c|c|c|}
\hline \multirow[b]{2}{*}{ Outcome } & \multicolumn{3}{|c|}{ TIMI score $\geq 4$} & \multicolumn{3}{|c|}{ TIMI score $<4$} \\
\hline & $\begin{array}{c}\text { With PCI } \\
\text { intervention }\end{array}$ & $\begin{array}{l}\text { Without PCI } \\
\text { intervention }\end{array}$ & $P$-value & $\begin{array}{c}\text { With PCI } \\
\text { intervention }\end{array}$ & $\begin{array}{l}\text { Without PCI } \\
\text { intervention }\end{array}$ & $P$-value \\
\hline $\begin{array}{l}\text { Malignant cardiac } \\
\text { arrhythmia }\end{array}$ & $9(6.9 \%)$ & $6(4.6 \%)$ & 0.919 & $2(5.3 \%)$ & $6(15.8 \%)$ & 0.012 \\
\hline LVSD & $19(15.2 \%)$ & $20(16.0 \%)$ & 0.046 & $4(11.4 \%)$ & $4(11.4 \%)$ & 0.286 \\
\hline Death & $12(9.2 \%)$ & $19(14.5 \%)$ & 0.009 & $2(5.3 \%)$ & 7 (18.4\%) & 0.004 \\
\hline
\end{tabular}

Data are expressed as number (percentage) of patients 
syndrome. The relationship between fQRS and the scoring system in patients with acute coronary syndrome was also reported (Bekler et al., 2015). Therefore, we used fQRS combined with the TIMI risk score to evaluate changes in condition and the prognostic outcomes for patients with AMI during hospitalization. With the combination of fQRS and the TIMI risk score, we concluded that the test had higher sensitivity and specificity in predicting the chance of malignant cardiac arrhythmia, LVSD, or death. In the group with a TIMI risk score of $<4$, we could see that in combination with the presence of fQRS, the numbers of cases with malignant cardiac arrhythmia, LVSD, and mortality were all significantly higher than those in the negative fQRS group. A study of changes in connexin protein 43 , intracellular calcium concentration, and the apoptotic process of ischemic myocardiocytes (Wang and Zhao, 2011) showed a relationship between early ventricular arrhythmia and an increase in calcium concentration that led to apoptosis during the acute phase of infarction. During myocardial ischemia, the conduction velocity of cells, including the surrounding normal myocardiocytes, decreased. A progressive gradient of rearrangement and destruction in connexins from non-ischemic to ischemic regions was observed (Liu et al., 2010). The concentration of connexins in the surrounding region of ischemia was much lower than the concentration between normal cells, thereby creating an inconsistent conduction velocity across the regions. As a result, the electrophysiological activity of myocardiocytes became asynchronous. Abnormal electrophysiological activity and slow conduction in ischemic myocardiocytes would usually generate a multiple notched QRS complex with low amplitude, known as fQRS. Morita et al. (2008) pointed out that fQRS existed in nearly $40 \%$ of patients with Brugada syndrome and was often observed in patients who had ventricular fibrillation episodes. The preferential occurrence of fQRS in the right precordial leads, especially in the higher intercostal spaces, corresponded to a localized conduction abnormality in the right ventricular outflow tract. The generation of multiple spike waves in fQRS was also seen in patients with Brugada syndrome who carried a defective gene $S C N 5 \mathrm{~A}$, which manifested as reduced conduction at multiple locations and would eventually lead to cardiac arrhythmia. This phenomenon could be used to predict the incidence of ventricular fibrillation, and the presence of fQRS was often used as a warning sign for high incidence of sudden cardiac arrest. Furthermore, the presence of fQRS in a different lead may also predict the severity of CAD (El-Dosouky and Abomandour, 2017; Eyuboglu et al., 2017).

To understand the correlation between PCI treatment and the short-term prognostic value of fQRS with the TIMI risk score, our study indicated that regardless of the TIMI risk score, patients with fQRS without PCI treatment would have a significantly higher mortality rate. A TIMI risk score of $<4$ points would be classified as medium risk and would usually lead to conservative medication as treatment if there were no signs of hemodynamic disturbance, frequent chest pain or changes in ECG. From our study, patients with a TIMI risk score of $<4$ would have a poor short-term prognosis when there are signs of fQRS. We showed that early PCI treatment could, to some degree, improve the condition and prevent malignant cardiac arrhythmia, LVSD, or even death. In addition, logistic regression analysis showed that malignant cardiac arrhythmia and fQRS were the independent predictive factors for increased mortality rate during hospitalization, while the TIMI score was not influential. Therefore, the combination of the TIMI risk score and fQRS in clinical practice can provide complete and objective prognostic evaluation of AMI patients. It plays a key role in instructing physicians to prescribe sufficient anti-coagulation treatment or intervention for patients with a score of $<4$. As a result, the mortality rate and the duration of hospitalization can be reduced, allowing the hospital to apply appropriate medical resources based on the risk to patients.

We have demonstrated the relationship between fQRS and short-term prognosis of patients with AMI (Sheng et al., 2014). Further studies showed that fQRS combined with the TIMI risk score could increase the sensitivity and specificity of the prognosis in AMI patients. For AMI patients with positive fQRS who undergo early revascularization, the incidence of cardiovascular events could be reduced. Moreover, the presence of fQRS could be used as an indicator for early intervention treatment in patients with a TIMI score of $<4$. 


\section{Compliance with ethics guidelines}

Qin-hui SHENG, Chih Chi HSU, Jian-ping LI, Tao HONG, and Yong HUO declare that they have no conflict of interest.

All procedures followed were in accordance with the ethical standards of the responsible committee on human experimentation (institutional and national) and with the Helsinki Declaration of 1975, as revised in 2008 (5). Informed consent was obtained from all patients for being included in the study. Additional informed consent was obtained from all patients for which identifying information is included in this article.

\section{References}

Antman EM, Cohen M, Bernink PJ, et al., 2000. The TIMI risk score for unstable angina/non-ST elevation MI: a method for prognostication and therapeutic decision making. JAMA, 284(7):835-842. https://doi.org/10.1001/jama.284.7.835

Bekler A, Barutçu A, Tenekecioglu E, et al., 2015. The relationship between fragmented QRS complexes and SYNTAX and Gensini scores in patients with acute coronary syndrome. Kardiol Pol, 73(4):246-254. https://doi.org/10.5603/KP.a2014.0208

Das MK, Khan B, Jacob S, et al., 2006. Significance of a fragmented QRS complex versus a Q wave in patients with coronary artery disease. Circulation, 113(21):24952501. https://doi.org/10.1161/CIRCULATIONAHA.105.595892

Das MK, Saha C, El Masry H, et al., 2007. Fragmented QRS on a 12-lead ECG: a predictor of mortality and cardiac events in patients with coronary artery disease. Heart Rhythm, 4(11):1385-1392. https://doi.org/10.1016/j.hrthm.2007.06.024

Das MK, Michael MA, Suradi H, et al., 2009. Usefulness of fragmented QRS on a 12-lead electrocardiogram in acute coronary syndrome for predicting mortality. Am J Cardiol, 104(12):1631-1637. https://doi.org/10.1016/j.amjcard.2009.07.046

El-Dosouky II, Abomandour HG, 2017. Fragmented QRS complex as a predictor of coronary artery disease in patients with acute coronary syndrome (A study from Egypt). Indian Heart J, 69(2):289-290. https://doi.org/10.1016/j.ihj.2017.02.018

Eyuboglu M, Kucuk U, Senarslan O, et al., 2017. Comparison of the presence of fragmented QRS complexes in the inferior versus the anterior leads for predicting coronary artery disease severity. Rev Port Cardiol, 36(2):89-93. https://doi.org/10.1016/j.repc.2016.07.008

Güngör B, Özcan KS, Karataş MB, et al., 2016. Prognostic value of QRS fragmentation in patients with acute myocardial infarction: a meta-analysis. Ann Noninvasive Electrocardiol, 21(6):604-612. https://doi.org/10.1111/anec.12357

Liu JC, Kou LY, Zhang LY, 2010. The effect of early revascuarlization on myocardial scarring and cardiac function. Clin Med China, 7:712-714 (in Chinese). https://doi.org/10.3760/cma.j.issn.1008-6315.2010.07.014

Morita H, Kusano KF, Miura D, et al., 2008. Fragmented QRS as a marker of conduction abnormality and a predictor of prognosis of Brugada syndrome. Circulation, 118(17): 1697-1704.

https://doi.org/10.1161/CIRCULATIONAHA.108.770917

Sheng QH, Hsu CC, Li JP, et al., 2014. Correlation between fragmented QRS and the short-term prognosis of patients with acute myocardial infarction. $J$ Zhejiang Univ-Sci B (Biomed \& Biotechnol), 15(1):67-74. https://doi.org/10.1631/jzus.B1300091

Tanriverdi Z, Dursun H, Colluoglu T, et al., 2017. Single derivation fragmented QRS can predict poor prognosis in successfully revascularized acute STEMI patients. Arq Bras Cardiol, 109(3):213-221. https://doi.org/10.5935/abc.20170099

Wang Y, Zhao HN, 2011. Investigation of changing and significance of connexin $43,\left[\mathrm{Ca}^{2+}\right]_{i}$ and apoptosis in early phase of acute myocardial ischemia. Chin $J$ Cardiac Pacing Electrophysiol, 4(25):349-352 (in Chinese).

Zhang RX, Chen SY, Zhao Q, et al., 2017. Fragmented QRS complex is a prognostic marker of microvascular reperfusion and changes in LV function occur in patients with ST elevation myocardial infarction who underwent primary percutaneous coronary intervention. Exp Ther Med, 13(6):3231-3238.

https://doi.org/10.3892/etm.2017.4380

\section{中文概要}

\section{题 目: 碎裂 QRS 波联合 TIMI 危险评分预测急性心肌 梗死患者的短期预后}

目 的: 探讨碎裂 QRS 波 (fQRS) 联合心肌梗死溶栓治 疗临床试验（TIMI）危险评分对急性心肌梗死 （AMI）患者短期预后的评估价值。

创新点：TIMI 危险评分常用于 AMI 患者入院即刻的风险 评估, TIMI 评分 $<4$ 分的患者被评定为中危组。 本研究发现, 无论 TIMI 评分如何, 出现 fQRS 而未行经皮冠状动脉介入治疗 (PCI) 的患者, 其死亡率均显著升高。fQRS 联合 TIMI 危险评分 更利于 AMI 患者的预后评估, TIMI 评分 $<4$ 分但 同时合并 $\mathrm{fQRS}$ 的患者, 可以从早期 PCI 介入治 疗获益。

方 法: 回顾 300例 AMI 患者的临床资料及院内诊治经过, 记录分析患者 fQRS 出现的时间、部位及其他临 床转归, 评价 fQRS 联合 TIMI 危险评分与患者临 床预后的关系。

结 论: (1) fQRS 联合 TIMI 危险评分可提高恶性心律 失常、左室收缩功能不全 (LVSD) 和死亡预测 的敏感度和特异度; (2) fQRS 阳性的 AMI 患者, 进行早期血运重建可降低患者心血管事件发生 率, fQRS 可能作为 TIMI 评分 $<4$ 分患者早期介入 治疗的指征。

关键词：急性心肌梗死；碎裂 QRS 波; TIMI 危险评分 